\title{
Percepção da Cadeia Produtiva da Carne Bovina por Pecuaristas no Estado do Mato Grosso
}

\author{
Beef Productive Chain Perception by Cattle Breeders in the State of Mato Grosso
}

\author{
Alexandre Nascimento; ${ }^{\mathrm{a}}$ Guilherme Cunha Malafaia ${ }^{\mathrm{b}}$; Gilberto Gonçalves Facco ${ }^{\mathrm{a}}$; Marcos Barbosa-Ferreiraa \\ Diego Gomes Freire Guidolin*a

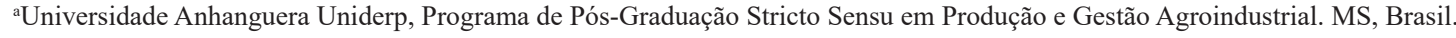

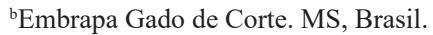 \\ *E-mail: diego.guidolin@educadores.net.br
}

\begin{abstract}
Resumo
O artigo objetivou identificar a percepção dos pecuaristas do Estado de Mato Grosso com relação ao sistema produtivo de suas propriedades na cadeia produtiva da carne bovina. Buscou-se atender a questão investigada: qual a relação entre a utilização de recursos da inovação tecnológica na cadeia produtiva da carne bovina? Utilizou-se a revisão teórica de agronegócio, cadeias produtivas e bovinocultura no Estado de Mato Grosso, sendo empregado o enfoque metodológico de pesquisa rápida (rapid assessment ou quick appraisal) com cinco representantes da classe ou instituições e 25 pecuaristas das cinco maiores cidades produtoras de bovinos do Estado de Mato Grosso (Cárceres, Vila Bela Santíssima Trindade, Juara, Alta Floresta e Juína), que representam 12,07\% do rebanho do Estado, e estão entre as 10 maiores cidades produtoras de gado bovino do país. A coleta dos dados, obtida por meio de questionário, propiciou verificar junto aos produtores de gado de corte e entidades que os representam: o uso de tecnologia, gestão, a relação de mercado e o ambiente institucional, que estruturam o funcionamento de suas propriedades na cadeia produtiva da carne bovina. Os produtores entrevistados demonstraram baixa percepção da gestão financeira e organizacional, assim como políticas das entidades representativas dos produtores. A percepção da relação entre produtores e frigoríficos indica a necessidade de melhoria na relação desses dois elos. Destacam-se os elevados índices dos direcionadores tecnológicos como manejo reprodutivo, genética do rebanho e sanidade do rebanho, assim como a capacitação de mão de obra e escala de produção.
\end{abstract}

Palavras-chave: Agronegócio. Bovinocultura de Corte. Pecuária.

\begin{abstract}
The article aimed to identify the cattle breeders perception in Mato Grosso State regarding the productive system of their properties in the beef productive chain. It was sought to answer the question investigated: what is the relationship between the use of technological innovation resources in the beef productive chain? Theoretical agribusiness review, productive chains and cattle-raising in the Mato Grosso State were used, by using the quick assessment or quick appraisal methodological approach with five representatives of the class

or institutions and 25 cattle breeders from the five largest cattle-producing cities in Mato Grosso State (Cárceres, Vila Bela Santíssima Trindade, Juara, Alta Floresta and Juina), which represent 12.07\% of the State's herd, and are among the 10 largest cattle producing cities in the country. The data collection, obtained through a questionnaire, made it possible to verify along with the cattle breeders and entities that represent them: the use of technology, management, the market relationship and the institutional environment that structure the operation of their properties in the beef productive chain. The interviewed producers showed a low perception of financial and organizational management, as well as policies of the producers' representative entities. The perception of the relationship between producers and slaughterhouses indicates the need for improvement in the relationship between these two links. High levels of technological indexes stand out, such as reproductive management, herd genetics and herd health, as well as the labor and production scale training.
\end{abstract}

Keywords: Agribusiness. Beef Cattle. Livestock.

\section{Introdução}

O Estado do Mato Grosso possui o maior contingente de bovinos no Brasil, com cerca de 30 milhões de cabeças. Durante janeiro e novembro de 2019 foram abatidos 5,27 milhões de animais no Estado, apresentando um crescimento de $6 \%$ sobre a quantidade registrada em igual período de 2018 (CARDOSO, 2019).

A crise econômica ocorrida em 2020, em decorrência da epidemia do novo Coronavírus, responsável pela COVID-19, não afetou drasticamente o agronegócio brasileiro, em especial a pecuária de corte, que manteve números crescentes de produção, exportação e renda no setor. Fatores que levaram ao bom andamento da atividade foram a escassez de oferta de animais prontos para o abate, resultado da maior matança de fêmeas em anos anteriores, quando o ciclo de preços era de baixa (CARDOSO, 2019). Outro fator positivo para a pecuária mato-grossense foi o aumento da exportação para a China, que cresceu no final de 2019, por conta do surgimento de focos da peste suína no país, que levou ao abate de boa parte do rebanho suíno chinês. A exportação para o gigante asiático se manteve acelerada durante 2020, sendo esse o principal destino da carne exportada pelo país e que ajudou a elevar o preço da arroba em patamares inéditos para a maioria dos criadores.

Independente do cenário de alta nos preços da arroba, que fazem aumentar os investimentos, por parte do pecuarista na 
atividade, é importante que se conheça a percepção do elo da produção na cadeia produtiva da carne bovina em relação aos direcionadores, que influenciam a atividade, com intuito de enfrentar entraves importantes à manutenção e ampliação de sua competitividade. Assim, este estudo teve como objetivo identificar a percepção dos pecuaristas do Estado de Mato Grosso com relação ao sistema produtivo de suas propriedades na cadeia produtiva da carne bovina.

\section{Desenvolvimento}

\subsection{Metodologia}

O procedimento metodológico utilizado no presente estudo foi o método de pesquisa rápida, adaptado do modelo utilizado por Famato (2007). Segundo a Agência Americana para Desenvolvimento Internacional - USAID (1996), o método de pesquisa rápida é recomendado para a avaliação do desempenho de sistemas, e se mostra apropriado nos casos em que: as informações descritivas e qualitativas são suficientes para a tomada de decisão, sendo necessária a compreensão das relações de causa e efeito que afetam o comportamento do sistema, sendo é preciso uma interpretação dos dados levantados; o objetivo está em gerar sugestões e recomendações, sendo necessário desenvolver melhores questionamentos, hipóteses e suposições para a posterior elaboração de um estudo formal, fundamentado em análises estatísticas. Este método de análise rápida (rapid assessment) se mostra adequado na análise de sistemas agroalimentares, em que os recursos de tempo e ou financeiros são escassos, ou quando o interesse está em obter conhecimento amplo sobre os componentes do sistema estudado (SILVA et al., 1998).

Ao todo, participaram da pesquisa, por meio de questionários e entrevistas semiestruturadas, 25 produtores e cinco representantes de agências e instituições ligadas à cadeia produtiva da carne bovina. Para a avaliação dos padrões de eficiência da cadeia produtiva, o estudo tomou por base a metodologia originalmente proposta por Van Duren et al. (1991) e adaptada por Famato (2007). Os produtores entrevistados possuíam suas propriedades localizadas um uma das cinco principais cidades produtoras de gado bovino no Estado de Mato Grosso (Cárceres, Vila Bela Santíssima Trindade, Juara, Alta Floresta e Juína), que juntas produziram 3.766 .451 cabeças em 2018, representando $12,07 \%$ do rebanho estadual.

Para a avaliação dos padrões de competitividade da cadeia foi considerada que a eficiência, em um sistema produtivo, é determinada por fatores diversos, sobre os quais é possível ou não o exercício de controle pelas empresas.

Os fatores, aqui classificados como direcionadores, foram agrupados em seis grandes blocos: tecnologia, gestão, relações de mercado e ambiente institucional. A partir de então, os direcionadores foram desdobrados em subfatores, que foram identificados e analisados quanto à intensidade em que contribuem, favorável ou desfavoravelmente, para a eficiência dos setores. Assim sendo, o direcionador de tecnologia em âmbito da produção foi, por exemplo, desdobrado nos subfatores, tecnologia disponível, qualidade das pastagens etc.

A partir das informações coletadas na pesquisa, cada indicador recebeu uma pontuação, e a análise realizada para cada direcionador se orientou pela escala de Likert (15), agregando as avaliações dos subfatores ao nível dos direcionadores. Para o tratamento estatístico dos dados foi utilizado o software SPSS da IBM.

\subsection{Resultados e Discussão}

A pesquisa de campo foi efetivada no período de fevereiro a abril de 2019. Buscou divulgar a percepção dos agenteschave da Cadeia Produtiva de Carne Bovina - CPCB quanto aos direcionadores: tecnologia, gestão, relação de mercado e ambiente institucional.

O direcionador de tecnologia se compõe por 10 (dez) fatores: adequação do sistema de produção, qualidade e manejo de pastagens, suplementação animal, manejo reprodutivo, genética do rebanho, sanidade do rebanho, integração lavoura e pecuária, controle zootécnico, assessoria técnica regular e manejo de rotina com os animais. Foi observada que a direcionadora tecnologia é percebida pelos produtores e agentes pesquisados como relevante à competitividade do segmento produção da CPCB em Mato Grosso (Quadro 1).

Quadro 1 - Percepção de pecuaristas do Estado de Mato Grosso quanto aos fatores direcionadores do uso de tecnologia dentro da propriedade rural

\begin{tabular}{|l|c|}
\hline \multicolumn{1}{|c|}{ Descrição } & Média $^{(\mathbf{1})}$ \\
\hline Adequação do sistema de produção & 4,43 \\
\hline Qualidade e manejo de pastagens & 4,00 \\
\hline Suplementação animal & 4,97 \\
\hline Manejo reprodutivo & 5,00 \\
\hline Genética do rebanho & 5,00 \\
\hline Sanidade do rebanho & 5,00 \\
\hline Integração lavoura e pecuária & 1,13 \\
\hline Controle zootécnico & 4,70 \\
\hline Assessoria técnica regular & 4,70 \\
\hline Manejo de rotina com os animais & 4,53 \\
\hline
\end{tabular}

(1) Média: Foram entrevistados 30 atores e utilizada a escala de Likert de 5 pontos, em que: 1) discordo totalmente, 2) discordo, 3) indiferente (ou neutro), 4) concordo e 5) concordo totalmente.

Fonte: Nascimento (2020).

As principais tecnologias adotadas, segundo o estudo, na CPCB no Mato Grosso são o manejo reprodutivo, a genética do rebanho e sua sanidade, apresentando média igual a cinco. Esses dados indicam uma preocupação com o ganho em produtividade e eficiência das propriedades. Oliveira et al. (2008) reportam que não basta ter a melhor genética, uma alta produtividade, uma nutrição equilibrada e de boa qualidade, se o manejo com os animais for incorreto. Além da qualidade, é relevante também o bem-estar do animal (LAMMENS et al., 2007). Pode-se destacar que na pesquisa Famato (2007), o Manejo e a sanidade dos rebanhos apresentaram resultados 
semelhantes. Porém, quando observada a genética dos animais se pode perceber uma evolução na importância dada pelo produtor em relação ao estudo anterior.

Outros fatores, que podem ser destacados, são a suplementação animal, o controle zootécnico e a assessoria técnica regular complementar, com médias de 4,97; 4,70 e 4,70 respectivamente. Observou-se uma evolução quanto à suplementação animal, assim como o controle zootécnico, quando comparados os resultados obtidos neste estudo em comparação ao de Famato (2007).

Para Rosa (2009), é viável elevar a produtividade por área por meio da adoção de tecnologias como pastejo rotacionado, adubação, irrigação e integração lavoura-pecuária, que poderiam ser escolhidas e usadas de forma alternada ou concomitantemente. Neste último, pode-se observar a média de 1,13, o que segundo os entrevistados ocorre, principalmente, pelo elevado custo, que impede a maioria dos produtores de realizarem os investimentos necessários para a adoção desta tecnologia.

Como se observa no Quadro 1, o uso de tecnologia na atividade pecuária dentro das empresas rurais é percebido, pelos produtores rurais, como relevante para a competitividade da CPCB.

O direcionador Gestão se compõe por dez fatores: capacitação de mão de obra, patrimônio, orçamento e fluxo de caixa, planejamento estratégico, controle de custos de produção, cálculo de indicadores financeiros, identificação do rebanho, comercialização, informatização da propriedade e escala de produção. A percepção dos produtores e dos agentes pesquisados está apresentada na Tabela 2 .

O diagnóstico efetivado apresentou quanto ao direcionador uso de tecnologia o menor resultado, tendo a média 3,59, evidenciando uma carência na gestão das organizações rurais. A pesquisa atual apontou resultados similares à pesquisa anterior (FAMATO, 2007), que neste direcionador recebeu pior avaliação, sendo considerada pelos autores como praticamente inexistente.

Destacam-se neste segmento a informatização e escala de produção com médias 5,00 e 4,50, respectivamente. Dessa forma, Cézar et al. (2004) afirmam que componentes tecnológicos aplicados à produção são importantes, mas ganhos em eficiência só se transformam em ganhos financeiros na medida em que a gestão dos processos produtivos seja eficaz. A utilização da informática nas empresas rurais, na última década, é admirável. De acordo com a pesquisa da Famato (2007), este item era um entrave a ser superado por essas organizações.

Pode-se destacar o orçamento e fluxo de caixa e patrimônio, com médias de 3,80 e 3,60, como indicadores importantes. Segundo os pecuaristas pesquisados, os processos existentes são relevantes e devem ser melhorados para o desenvolvimento das atividades. Para Melz, Franco e Torres (2009), tal situação é justificada porque na pecuária de corte, historicamente, nunca foi necessária a realização destas verificações, pois a competitividade das propriedades não era comprometida.

Complementar a esses indicadores se tem a capacitação de mão de obra e planejamento estratégico, com médias 3,60 e 3,40, respectivamente. Percebe-se que a capacitação de mão de obra, conforme relatos dos produtores, é apropriada, com satisfação das técnicas utilizadas. De acordo com a Famato (2018), o Estado de Mato Grosso e a iniciativa privada investiram em cursos e programas de qualificação para o setor e qualificaram $37,9 \%$ dos empregos.

Ainda, no direcionador de gestão, pode-se observar que o Cálculo de Indicadores Financeiros, Controle de Custos de Produção e Comercialização apresentam médias de 1,70, 2,90 e 2,90, valores que podem ser considerados baixos e que apontam a baixa percepção que os produtores têm em relação a esses direcionadores. Percepção contrária à recomendação de Viana e Silveira (2008), que dizem haver na pecuária a necessidade de maior controle financeiro, visando melhorar a produtividade e a competitividade, auxiliando no processo de gestão das empresas rurais.

Como se observa no Quadro 2, a gestão empresarial na atividade pecuária dentro das empresas rurais é percebida, pelos produtores rurais, com particularidades que devem ser observadas com atenção e trabalhadas para que os produtores aumentem a importância dada a gestão na propriedade. Comparando os desafios da CPCB com outras cadeias produtivas se pode destacar o estudo sobre a competitividade da cadeia produtiva do leite, em Pernambuco, realizado pela EMBRAPA Gado de Leite (2009). Neste estudo se levantou que os produtores devem atentar para a capacitação, a competência administrativa e gerencial (conhecimento de fluxos de mercado e de comercialização) e compromisso com a qualidade.

Quadro 2 - Percepção dos pecuaristas do Estado de Mato Grosso quanto aos fatores direcionadores da gestão na propriedade

\begin{tabular}{|l|c|}
\hline \multicolumn{1}{|c|}{ Descrição } & Média $^{\text {(2) }}$ \\
\hline Capacitação de Mão de Obra & 3,60 \\
\hline Patrimônio & 3,60 \\
\hline Orçamento e Fluxo de Caixa & 3,80 \\
\hline Planejamento Estratégico & 3,40 \\
\hline Controle de Custos de Produção & 2,90 \\
\hline Cálculo de Indicadores Financeiros & 1,70 \\
\hline Identificação do Rebanho & 3,20 \\
\hline Comercialização & 2,90 \\
\hline Informatização da Propriedade & 5,00 \\
\hline Escala de Produção & 4,00 \\
\hline
\end{tabular}

(2) Média: Foram entrevistados 30 atores e utilizada a escala de Likert de 5 pontos, em que: 1) discordo totalmente, 2) discordo, 3) indiferente (ou neutro), 4) concordo e 5) concordo totalmente.

Fonte: Nascimento (2020).

Segundo Batalha e Silva (2010), dentro de uma cadeia agroindustrialé possível visualizarno mínimo quatro mercados: entre os produtores de insumos e os produtores rurais; entre produtores rurais e agroindústria; entre agroindústria e distribuidores; e, entre distribuidores e consumidores finais. 
Nesta pesquisa se estruturou o direcionador Relação de Mercado em dois fatores: relação entre produtor e fornecedor, relação entre produtor e frigorífico (Quadro 3).

Quadro 3 - Percepção dos pecuaristas do Estado de Mato Grosso quanto aos fatores direcionadores do fator de Relação de Mercado

\begin{tabular}{|l|c|}
\hline \multicolumn{1}{|c|}{ Descrição } & Média $^{(3)}$ \\
\hline Relação produtor-fornecedor & 5,00 \\
\hline Relação produtor-frigorífico & 3,10 \\
\hline
\end{tabular}

(3) Média: Foram entrevistados 30 atores e utilizada a escala de Likert de 5 pontos, em que: 1) discordo totalmente, 2) discordo, 3 ) indiferente (ou neutro), 4) concordo e 5) concordo totalmente. Fonte: Nascimento (2020).

A percepção dos entrevistados referente ao fator relação entre produtor e fornecedor se apresentou com média 5,00, resultado similar ao colhido nos dados da Famato (2007). Segundo relato de um pecuarista entrevistado: "a relação com os fornecedores acontece da melhor forma possível, os insumos são comprados no comércio local e a relação de amizade e parentesco tem influência nas escolhas de compras".

Por outro lado, a relação entre os produtores e frigoríficos apresenta média 3,10. Entre os principais gargalos se pode apontar a ausência de acompanhamento técnico e satisfação nas vendas dos produtos, assim como a relação de confiança com os frigoríficos. Tais fatos dificultam uma fidelidade entre os produtores e frigoríficos, tendo os produtores ido em busca de preços melhores para suas vendas. Outro ponto levantado pela pesquisa é a concentração de frigoríficos, o que dificulta a concorrência e, consequentemente, o preço de venda dos animais. Concernente à relação entre produtor e frigorífico, os resultados obtidos demonstraram ser uma relação conflituosa, com baixa confiança entre estes agentes (GOLANI; MOITA, 2010). Tal fato é apresentado como um dos maiores entraves que elevam os custos da CPCB (BUAINAIN; BATALHA, 2007).

O direcionador relativo ao Ambiente Institucional se desdobrou em sete indicadores: acesso à inovação tecnológica, política e fiscalização tributárias, política e fiscalização ambiental, política de crédito agropecuário, política e fiscalização sanitária, legislação oficial e regularização fundiária e organização dos produtores, apresentando uma média de 3,64 (Quadro 4).

Quadro 4 - Percepção dos pecuaristas do Estado de Mato Grosso quanto aos direcionamentos do bloco de Ambiente Institucional

\begin{tabular}{|l|c|}
\hline \multicolumn{1}{|c|}{ Descrição } & Média $^{(4)}$ \\
\hline Acesso à inovação tecnológica & 2,20 \\
\hline Política e fiscalização sanitária & 4,60 \\
\hline Política e fiscalização ambiental & 4,80 \\
\hline Política de crédito agropecuário & 3,40 \\
\hline Política e fiscalização sanitária & 4,70 \\
\hline Legislação oficial e regularização fundiária & 2,80 \\
\hline Organização dos produtores & 3,00 \\
\hline
\end{tabular}

(4) Média: Foram entrevistados 30 atores e utilizada a escala de Likert de 5 pontos, em que: 1) discordo totalmente, 2) discordo, 3) indiferente (ou neutro), 4) concordo e 5) concordo totalmente.

Fonte: Nascimento (2020).
Estes números podem ser expressos pelos elevados índices de satisfação dos pesquisados com relação aos fatores política e fiscalização ambiental, política e fiscalização sanitária e políticas e fiscalização tributárias, com médias 4,80, 4,70 e 4,60 respectivamente, diferentemente dos dados apresentados na pesquisa Famato (2007), que divulgaram apenas como favorável à política e fiscalização sanitária. Pode-se associar o aumento desses números às exigências, regulamentos e normas que a exportação de carne precisa se adequar para comercializar com os países importadores (BARBOSA; CALEMAN, 2016).

Os indicadores de política de crédito agropecuário, com média 3,40, e organização dos produtores, com média 3,00, apontam a necessidade de melhorias na CPCB, uma vez que, de acordo com um representante de entidade de classe: “os grandes pecuaristas utilizam de recursos próprios para desenvolverem suas atividades. Por outro lado, temos os pequenos produtores com dificuldade de aquisição de crédito, principalmente, pela ausência de documentos que comprovam a aquisição da terra e serviriam como garantia".

Os pontos negativos do direcionador ambiente institucional são acesso à inovação tecnológica e legislação oficial e regularização fundiária, com médias 2,20 e 2,80, respectivamente. $\mathrm{O}$ primeiro se deve, principalmente, a ausência de Universidades e centros de pesquisas próximo as regiões com maior produção de gados bovinos. O investimento em pesquisa aumenta o índice de produtividade (GASQUES et al., 2008). O segundo fator negativo do direcionador ambiente institucional retrata certa insatisfação dos pecuaristas pesquisados com as ações desenvolvidas pelos órgãos competentes, fator que prejudica a credibilidade de compra e venda de áreas por razões de grilagem de terras. Dados estes que coincidem com os dados apresentados em 2007, pela Famato.

De acordo com Lima et al. (2005), Mato Grosso implantou, em 2000, o sistema de licenciamento ambiental em propriedades rurais (SLAPR), que utiliza informações derivadas de sensores orbitais, bases cartográficas e de informações de campo gerenciadas e/ou, processadas por softwares de geoprocessamento e por gerenciadores de bancos de dados espaciais. Apesar de visualizarem, positivamente, a proteção ao meio ambiente, os entrevistados afirmam que o formato, mais do que o processo em si, tem gerado vários problemas e que precisa de alinhamento de planejamento e ações.

Como se observa na Tabela 4, o ambiente institucional na atividade pecuária dentro das empresas rurais é percebido, pelos produtores rurais, como necessitando de adequações de alguns fatores para que o ganho de competitividade e da cadeia seja alcançado.

Nesse cenário se pode observar a oportunidade para elaboração de estratégias que objetivem a disponibilização de inovação aos produtores em toda a cadeia, assim como a organização dos pecuaristas de forma a obterem ganhos de 
eficiência e de produtividade.

\section{Conclusão}

Os agentes da cadeia produtiva da carne bovina no Estado do Mato Grosso pesquisados apresentam baixa percepção da gestão financeira e organizacional e visualizam a necessidade de políticas das entidades representativas para a organização coletivas visando maior competitividade.

A percepção da relação entre produtores e frigoríficos indica a necessidade de melhoria na relação desses dois elos da cadeia produtiva da carne bovina no Estado do Mato Grosso.

Pode-se destacar os elevados índices dos direcionadores tecnológicos como manejo reprodutivo, genética do rebanho e sanidade do rebanho, assim como a capacitação de mão de obra e escala de produção. Esses fatores são tidos pelos produtores como muito importantes para o desenvolvimento da atividade.

\section{Referências}

BARBOSA, L.C.; CALEMAN, S.M.Q. Sustentabilidade em Sistemas Agroindustriais: um estudo multicasos da carne bovina de Mato Grosso do Sul, Brasil. Org. Rurais Agroind., v.18, n.4, p.315-331, 2016.

BATALHA, M. O.; SILVA, A. L. Gerenciamento de sistemas agroindustriais: definições e correntes metodológicas. In: BATALHA, M.O. (Coord.). Gestão agroindustrial. São Paulo: Atlas, 2010.

BUAINAIN, A.; BATALHA, M.O. Cadeia produtiva da carne bovina. Série Agronegócios. Brasília: IICA: MAPA/SPA, 2007.

CARDoso, D. Pecuária de Mato Grosso está baseada no otimismo para 2020. DBO, São Paulo. Disponível em: https:// www.portaldbo.com.br/pecuaria-de-mato-grosso-e-so-otimismopara-2020/. Acesso em: 17 jun. 2020.

CÉZAR, I. M. et al. Perspectivas da gestão em sistemas de produção animal: desafios a vencer diante de novos paradigmas. In: REUNIÃO ANUAL DA SOCIEDADE BRASILEIRA DE ZOOTECNIA, 41, 2004, Campo Grande. Anais. Campo Grande: SBZ, 2004.

EMBRAPA GADO DE LEITE. Competitividade da cadeia produtiva do leite em Pernambuco. Juiz de Fora: Embrapa Gado de Leite, 2009.

FAMATO. Federação da Agricultura e Pecuária do Estado de Mato Grosso, et al. Diagnóstico da Cadeia Produtiva Agroindustrial da Bovinocultura de Corte do Estado de Mato Grosso. Cuiabá, 2007

FAMATO- Federação Da Agricultura e Pecuária do Estado do Mato Grosso. Disponível em: http://sistemafamato.org.br/. Acesso em 20 jan. 2020.

GASQUES, J.G.; BASTOS, E.T.; BACCHI, M.R.P. Produtividade e fontes de crescimento da agricultura brasileira. In: DE NEGRI, J.A.; KUBOTA, L.C. Politicas de incentivo à inovação tecnológica no Brasil. Brasília: Ipea, 2008. p.435-459.

GOLANI, L.; MOITA, R. Oligopsônio dos frigoríficos: uma análise empírica de poder de mercado. Insper Working Paper, Insper Instituto de Ensino e Pesquisa, 2010.

LAMMENS, V. et al. Survey of pork quality in relation to preslaughter conditions, slaughterhouse facilities, and quality assurance. Meat Scie., v.75, p.381-387, 2007. doi: 10.1016/j. meatsci.2006.08.001

LIMA, R.C.A.; MIRANDA, S.H.G.; GALLI, F. Febre aftosa: impacto sobre as exportações brasileiras de carnes e contexto mundial das barreiras sanitárias. São Paulo: Ícone/CEPEA, 2005.

NASCIMENTO, A. Percepção da cadeia produtiva da carne bovina por pecuaristas nas cinco maiores cidades produtoras no estado do Mato Grosso. Campo Grande: UNIDERP, 2020.

MELZ, L.J.; FRANCO, C.; TORRES, A.L. Custos de produção de gado bovino: um enfoque da contabilidade de custos. In: CONGRESSO DA SOCIEDADE BRASILEIRA DE ECONOMIA, ADMINISTRAÇÃO E SOCIOLOGIA RURAL, 47. 2009, Porto Alegre. Anais. Porto Alegre, 2009.

OLIVEIRA, C.B.; BORTOL, E.C.; BARCELLOS, J.O.J. Diferenciação por qualidade da carne bovina: a ótica do bemestar animal. Ciênc. Rural, v.38, n.7, p. 2092-2096, 2008.

ROSA, F.R.T. Fatores críticas da competitividade da cadeia produtiva da carne bovina do Estado de São Paulo. São Carlos: UFSCar, 2009.

SILVA, C.A.B., LEITE, C.A.M., MUNIZ, J.N. O Enfoque sistêmico do produto. In: SILVA, C.A.B. Textos de referência do workshop do sistema agroindustrial do leite. SEBRAE, Nacional, 1998.

USAID - United States Agency for International Development. Using rapid appraisal methods. Disponível em: http://www.usaid. gov/pubs/usaid_eval/pdf_docs/pnaby209.pdf. Acesso em: 23 out. 2019.

VAN DUREN, E.; MARTIN, L.; WESTGREN, R. Assessing the competitiveness of Canada's agrifood industry. Canadian J. Agricul. Economics, v. 39, p.727-738, 1991.

VIANA, J.G.A.; SILVEIRA, V.C.P. Custos de produção e indicadores de desempenho: metodologia aplicada a sistemas de produção de ovinos. Custos e @gronegócioonline, v. 4, n. 3, set/ dez. 2008. Disponível em: http://www.custoseagronegocioonline. com.br/numero3v $4 /$ custos $\% 20 \mathrm{de} \% 20$ producao $\% 20$ ovinos.pdf. Acesso em: 10 fev. 2020. 